\title{
Phylogenomic analysis and revised classification of atypoid mygalomorph spiders (Araneae, Mygalomorphae), with notes on arachnid ultraconserved element loci
}

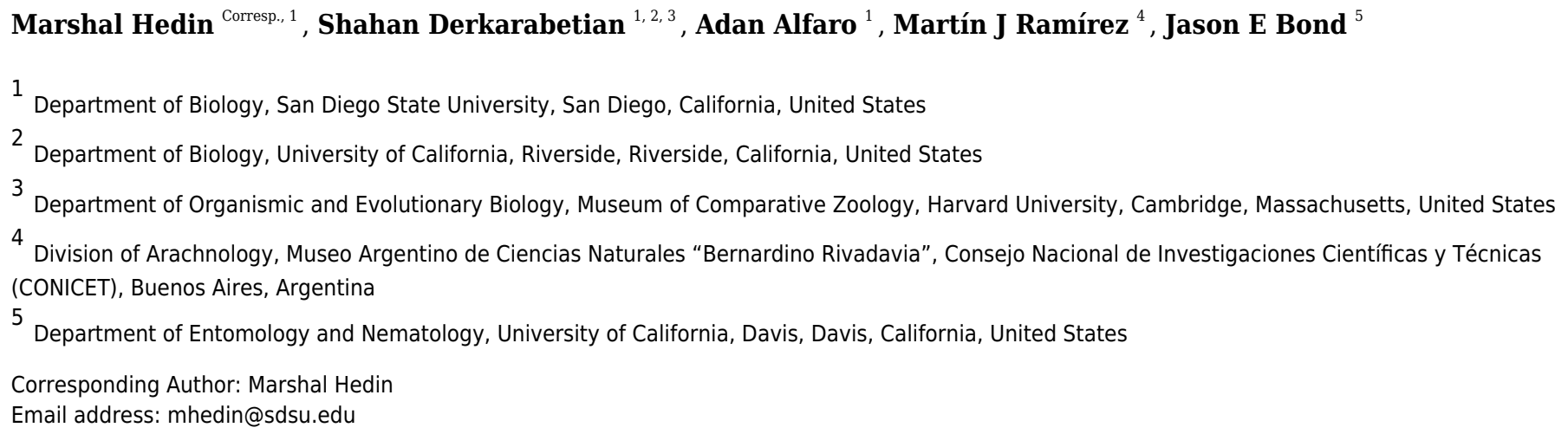

The atypoid mygalomorphs include spiders from three described families that build a diverse array of entrance web constructs, including funnel-and-sheet webs, purse webs, trapdoors, turrets and silken collars. Molecular phylogenetic analyses have generally supported the monophyly of Atypoidea, but prior studies have not sampled all relevant taxa. Here we generated a dataset of ultraconserved element loci for all described atypoid genera, including taxa (Mecicobothrium and Hexurella) key to understanding familial monophyly, divergence times, and patterns of entrance web evolution. We show that the conserved regions of the arachnid UCE probe set target exons, such that it should be possible to combine UCE and transcriptome datasets in arachnids. We also show that different UCE probes sometimes target the same protein, and under the matching parameters used here show that UCE alignments sometimes include non-orthologs. Using multiple curated phylogenomic matrices we recover a monophyletic Atypoidea, and reveal that the family Mecicobothriidae comprises four separate and divergent lineages. Fossilcalibrated divergence time analyses suggest ancient Triassic (or older) origins for several relictual atypoid lineages, with late Cretaceous / early Tertiary divergences within some genera indicating a high potential for cryptic species diversity. The ancestral entrance web construct for atypoids, and all mygalomorphs, is reconstructed as a funnel-and-sheet web. 


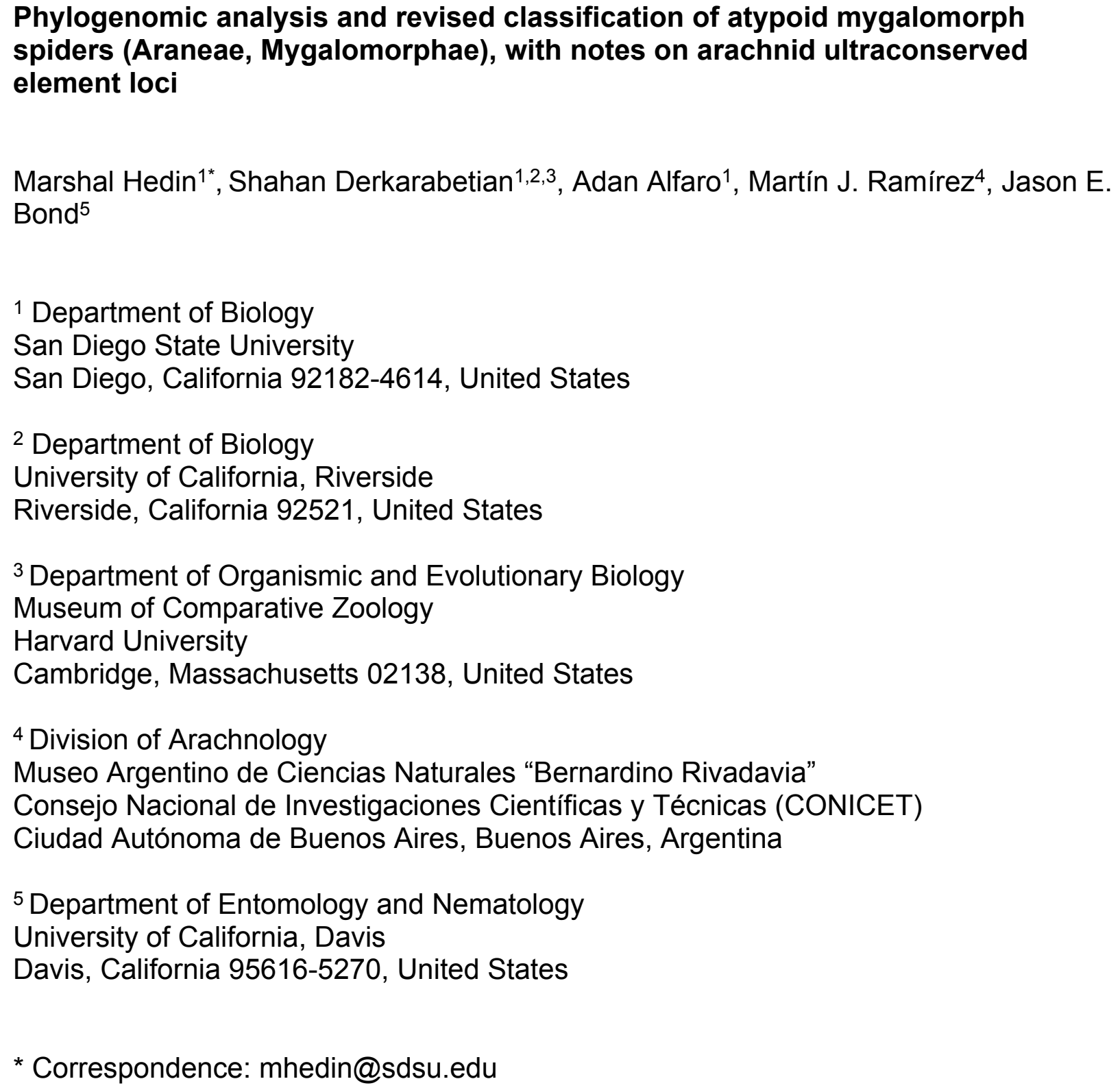




\section{Abstract}

38

39

40

41
The atypoid mygalomorphs include spiders from three described families that build a diverse array of entrance web constructs, including funnel-and-sheet webs, purse webs, trapdoors, turrets and silken collars. Molecular phylogenetic analyses have generally supported the monophyly of Atypoidea, but prior studies have not sampled all relevant taxa. Here we generated a dataset of ultraconserved element loci for all described atypoid genera, including taxa (Mecicobothrium and Hexurella) key to understanding familial monophyly, divergence times, and patterns of entrance web evolution. We show that the conserved regions of the arachnid UCE probe set target exons, such that it should be possible to combine UCE and transcriptome datasets in arachnids. We also show that different UCE probes sometimes target the same protein, and under the matching parameters used here show that UCE alignments sometimes include nonorthologs. Using multiple curated phylogenomic matrices we recover a monophyletic Atypoidea, and reveal that the family Mecicobothriidae comprises four separate and divergent lineages. Fossil-calibrated divergence time analyses suggest ancient Triassic (or older) origins for several relictual atypoid lineages, with late Cretaceous / early Tertiary divergences within some genera indicating a high potential for cryptic species diversity. The ancestral entrance web construct for atypoids, and all mygalomorphs, is reconstructed as a funnel-and-sheet web. 
60

61

62

63

64

65

66

67

68

69

70

71

72

73

74

75

76

77

\section{Introduction}

Phylogenetic evidence now overwhelmingly indicates that the mygalomorph spiders, including trapdoor spiders and their kin, are divided into the primary clades Avicularioidea and Atypoidea (Hedin \& Bond, 2006; Bond et al. 2012; Hamilton et al. 2016; Garrison et al. 2016, Wheeler et al. 2017; Hedin et al. 2018a; Fernández et al. 2018, Opatova et al. 2019). Avicularioidea includes the most familiar mygalomorphs (e.g., tarantulas), and the bulk of known taxonomic diversity (World Spider Catalog, 2019). Phylogenomic analyses based on sequence-capture data have now dramatically changed our understanding of family-level diversity and interrelationships within the avicularioids (Hamilton et al. 2016; Hedin et al. 2018a; Opatova et al. 2019), with many families previously suspected of non-monophyly now known to constitute multiple independent lineages (Hedin et al. 2018a; Opatova et al. 2019).

Avicularioids are sister to Atypoidea, the latter group representing an old taxonomic hypothesis (Simon, 1892). Atypoidea was first suggested then refuted by morphology, then supported by few-gene molecular studies, and is now seemingly confirmed by phylogenomic approaches. This clade, sometimes referred to as the "atypical tarantulas" (Gertsch, 1949), includes three described families (Antrodiaetidae, Atypidae, Mecicobothriidae) whose members possess dorsal abdominal tergites (Fig. 1B, E, G). These tergites are believed to represent the vestiges of abdominal segmentation, as found in spider relatives and early-diverging spiders. Adult male atypoids possess a palpus with a conductor, females have bipartite spermathecal organs, and members of both sexes typically possess six spinnerets (Eskov \& Zonstein, 1990). This clade is relatively ancient, as multiple fossil genera placed within the three described families are known from the Lower Cretaceous (100-112 MYA) of Mongolia (Eskov \& Zonstein, 1990). Dalla Vecchia and Selden (2013) placed the Triassic (210-215 MYA) Friularachne into Atypoidea, but left the family-level placement unspecified.

Atypoids utilize silk to build many different types of burrow entrance constructs (Coyle, 1986). The mecicobothriid genera Mecicobothrium, Megahexura, Hexura, and Hexurella are all ground-dwelling spiders found living under objects or in earthen crevices, using elongate spinnerets to build silken funnel-and-sheet webs (Gertsch \& Platnick, 1979; Costa \& Pérez-Miles, 1998; pers. obs.; Fig. 1A, B, D, F). The atypid genera either live in subterranean burrows with open silk-lined entrances (Calommata), or build cryptic silken capture tubes extending horizontally or vertically from burrow entrances (all atypid genera, Schwendinger, 1990; Fourie, Haddad \& Jocqué, 2011; Fig. 1C). Finally, the antrodiaetids live in subterranean burrows with silken turret or collapsible collar entrances (Antrodiaetus), or build trapdoors to cover their burrows (Aliatypus, Coyle, 1971; Fig. 1E, G, H). Most atypoid taxa are distributed on northern continents, although Mecicobothrium occurs in southern South America, and Calommata species are found in east Asia and throughout sub-Saharan Africa (World Spider Catalog, 2019).

Faircloth et al. (2012) first used the sequence capture of ultraconserved elements (UCEs) in phylogenomic analyses of various amniote lineages. In vertebrates more 
104 generally, core UCE regions show extreme sequence conservation, making design of

105 broad-utility nucleotide baits possible (e.g., for all fishes, all amniotes, etc.). The function

106 and genomic position of vertebrate UCEs has remained somewhat elusive, although

107 most are believed to have regulatory functions and lie outside of exons (e.g., Bejerano

108 et al. 2004; Polychronopoulos et al. 2017; McCole et al. 2018). More recently, UCE

109 baits have been designed for megadiverse arthropod lineages, including arachnids and

110 multiple insect orders (Faircloth et al. 2015; Faircloth, 2017). Bossert and Danforth

111 (2018) showed that a universal set of 100 UCEs are shared across all arthropods, and

112 that these "core" UCEs are entirely or partially exonic in origin, thus differing from

113 vertebrate UCEs. In this paper we further explore the function of genomic regions

114 captured by the arachnid UCE bait set. This set was tested in situ by Starrett et al.

115 (2017), and has been used in multiple phylogenomic studies (Derkarabetian et al.

116 2018a; Hedin et al. 2018a, 2018b; Wood et al. 2018). Knowing the functional role of

117 arachnid UCEs has clear importance in phylogenomic analyses, potentially impacting

118 sequence alignment, model selection, data partitioning, detection of paralogy, and so

119 on. This is particularly true in a lineage such as spiders, where an ancient whole-

120 genome duplication event has occurred (Clarke et al. 2015; Schwager et al. 2017),

121 perhaps complicating orthology assignment.

122

123

124

125

126

127

128

129

130

131

132

133

134

135

136

137

138

139

140

141

142

143

144

145

146

147

148

149

Interrelationships within Atypoidea have varied considerably in past molecular phylogenetic studies (Fig. 2), and no prior studies have simultaneously sampled all known (described) atypoid genera. Here we present such an analysis with all genera, including key taxa such as Mecicobothrium and the diminutive Hexurella, neither included in prior molecular phylogenetic analyses. Using an annotated UCE locus set with BLAST evidence for gene function and orthology, we demonstrate that Atypoidea is monophyletic, while revealing multiple cases of non-monophyly within described families. Early-diverging atypoid lineages are often species-poor (approximating monotypic) and use silk to build funnel-and-sheet webs, while more diverse silken constructs have evolved in derived atypoid lineages. Similar patterns of species and web diversification occur in parallel in the avicularioids (Opatova et al. 2019).

\section{Materials \& Methods}

Taxon sampling. Representatives of all nine described atypoid genera (World Spider Catalog, 2019) were sampled. Within genera, the sample included all three known species in the synonymized genus Atypoides (species now included in Antrodiaetus, Hendrixson \& Bond, 2007), two species of originally-described Antrodiaetus which span the hypothesized root node of this taxon (Hendrixson \& Bond, 2007, 2009), two species of Aliatypus which span the hypothesized root node of this genus (Satler et al. 2011), both described Hexura species, two geographically separated species of Hexurella, two geographically distant populations of the monotypic Megahexura fulva, and two species of the genus Sphodros. Only Mecicobothrium, Calommata and Atypus were represented by single specimens (Table S1). To confirm atypoid monophyly we sampled a handful of representative avicularioid taxa, including genera representing multiple early-diverging avicularioid lineages (Bond et al. 2012; Hedin et al. 2018a; Opatova et al. 2019). Mygalomorphs are sister to araneomorph spiders - we used an

Peer) reviewing PDF | (2019:01:34648:1:2:NEW 25 Mar 2019) 
150 early-diverging araneomorph lineage (Hypochilus) to root trees. In total, we gathered 151 original UCE data for 15 specimens; data for 12 specimens were taken from previous 152 studies (Starrett et al. 2017; Hedin et al. 2018a; Table S1). Permits for the collection of

153 Australian specimens were granted by the Queensland Environmental Protection

154 Agency (permit \#WISP01242003).

155

DNA extraction. Most specimens were preserved for DNA studies (preserved in high percentage ethyl alcohol at $-80 \mathrm{C}$ ), and genomic DNA was extracted from leg tissue using the Qiagen DNeasy Blood and Tissue Kit (Qiagen, Valencia, CA). For a handful of tissues preserved in $70-80 \%$ we used either standard phenol/chloroform extractions with 24-hour incubation for lysis, or used a modification of the Tin, Economo \& Mikheyev (2014) protocol (Table S1). All extractions were quantified using a Qubit Fluorometer (Life Technologies, Inc.) and quality was assessed on agarose gels. Between 22-500 ng total DNA was used for UCE library preparation (Table S1).

UCE data collection \& matrix assembly. UCE data were collected in multiple library preparation and sequencing experiments. Up to $500 \mathrm{ng}$ of genomic DNA was used in sonication, using a Covaris M220 Focused-ultrasonicator. Library preparation followed methods previously used for arachnids as in Starrett et al. (2017), Derkarabetian et al. (2018a, 2018b), and Hedin et al. (2018a, 2018b). Target enrichment was performed using the MYbaits Arachnida 1.1K version 1 kit (Arbor Biosciences; Faircloth, 2017) following the Target Enrichment of Illumina Libraries v. 1.5 protocol (http://ultraconserved.org/\#protocols). Libraries were sequenced on an Illumina HiSeq 2500 (Brigham Young University DNA Sequencing Center).

Raw demultiplexed reads were processed with the PHYLUCE pipeline (Faircloth, 2016). Quality control and adapter removal were conducted with the ILLUMIPROCESSOR wrapper (Faircloth, 2013). Assemblies were created with VELVET (Zerbino et al. 2008) and/or TRINITY (Grabherr et al. 2011), both at default settings. When contigs from both assemblies were available, these were combined for probe matching, retrieving assembly-specific UCEs and overall increasing the number of UCEs per sample relative to using only a single assembly method. Contigs were matched to probes using minimum coverage and minimum identity values at liberal values of 65 . UCE loci were aligned with MAFFT (Katoh \& Standley, 2013) and trimmed with GBLOCKS (Castresana, 2000; Talavera \& Castresana, 2007), using --b1 0.5 --b2 0.5 --b3 6 --b4 6 settings in the PHYLUCE pipeline.

UCE locus annotation, Matrix filtering, and Phylogenomic analyses. 698 loci were found in a PHYLUCE $70 \%$ occupancy matrix. For the consensus sequence from each locus alignment, BLAST X searches in Geneious 10.1 (Biomatters Ltd.) were conducted against a local database (max e value of $1 \times 10^{-10}$ ) comprising protein sequences for four arachnid taxa: Limulus polyphemus (https://www.ncbi.nlm.nih.gov/genome/787), Ixodes scapularis (https://www.ncbi.nlm.nih.gov/genome/?term=523), Stegodyphus mimosarum (https://www.ncbi.nlm.nih.gov/genome/?term=12925) and Parasteatoda tepidariorum (https://www.ncbi.nlm.nih.gov/genome/?term=13270). 
196 BLAST annotation indicated that essentially all spider UCE loci are either entirely exonic, or

197 exons with flanking introns (see Results). This annotation information allowed us to further

198 curate PHYLUCE alignments in several ways. First, we discovered that some individual loci were

199 part of the same protein, likely exons (or parts thereof) separated by introns (see Results).

200 Second, annotation indicated that some UCE loci could potentially include paralogs of the

201 same protein, or orthologs of two or more different proteins. We thus visually inspected all

202 UCE locus alignments and excluded loci with non-orthology as evidenced by congeneric taxa

203 with divergent sequences, using RAxML gene trees (see below) to confirm this non-orthology.

204 Finally, annotation allowed us to define exon/intron boundaries, and exclude a majority of

205 intron sequence for some analyses.

206

207 Three matrices were assembled for phylogenomic analyses, including 1) 70\%

208 occupancy PHYLUCE unfiltered (including same protein duplicates, some loci with non-

209 orthologs), 2) 70\% exon + intron, no "paralogs", retaining one UCE locus from a set

210 including duplicates (alignment with most sequences, or longest alignment if

211 approximately same number of taxa), 3) $70 \%$ filtered as \#2 above, plus using stricter

212 GBLOCKS settings (--b1 0.5 --b2 0.85 --b3 4 --b4 8) to further trim alignments. We

213 visually checked to confirm that these trimmed alignments comprised mostly exon data.

214 Unpartitioned and partitioned concatenated maximum likelihood analyses were run for

215 each dataset above. Unpartitioned analyses were conducted with RAxML version 8.2

216 (Stamatakis, 2014) using a complex GTRGAMMA model and 200 rapid bootstrap

217 replicates. Partitioned maximum likelihood analyses were conducted using IQ-TREE

218 (Nguyen et al. 2015; Chernomor, von Haeseler \& Minh, 2016) with partitions and

219

220

221

222

223

224

225

226

227

228

229

230

231

232

233

234

235

236

237

238

239

240

241 models determined using ModelFinder (Kalyaanamoorthy et al. 2017), and support estimated via 1000 ultrafast bootstrap replicates (Hoang et al. 2018). Finally, we used SVDquartets (Chifman \& Kubatko 2014; Chifman \& Kubatko 2015) with $n=500$ bootstraps, as implemented in PAUP* $4.0 a 163$ (Swofford, 2003).

Web Evolution and Divergence Time Analysis. Mesquite version 3.51 (Maddison \& Maddison, 2018) was used to reconstruct ancestral states for entrance web constructs, with tip values scored as seven different discrete states. Tip scorings were derived from published literature (references in Introduction), supplemented with original observation. Maximum likelihood reconstructions were produced using the one-parameter Markov kstate model (Lewis, 2001), using the RAxML exon only topology as input.

We estimated absolute divergence times using the lognormal relaxed clock model (Thorne, Kishino \& Painter, 1998) implemented in Phylobayes 4.1c (Lartillot \& Philippe, 2004). We used the exon only matrix, with the RAxML topology as a constraint tree. Four MCMC chains were run in parallel, stopping after 30,000 points. Analyses were checked for convergence, and considered converged when the largest discrepancy observed across bipartitions (maxdiff) was equal to 0 . Posterior estimates of ages and highest posterior density (HPD) values were summarized on a single target tree from all input trees using TreeAnnotator (Bouckaert et al. 2014). Three fossil calibrations were used, with a soft bounds model (Yang \& Rannala, 2006) and a birth death prior on divergence times, as follows: 1 ) minimum age for the root node of mygalomorphs $=240$ MYA, based on Rosamygale, the oldest known mygalomorph fossil (Selden \& Gall, 
242

243

244

245

246

247

248

249

250

251

252

253

254

255

256

257

258

259

260

261

262

263

264

265

266

267

268

269

270

271

272

273

274

275

276

277

278

279

280

281

282

283

284

285

286

287

1992). This taxon was placed by original authors as an avicularioid, but is treated more conservatively here. 2) minimum age for the root node of Atypoidea $=210$ MYA, based on Friularachne (Dalla Vecchia \& Selden, 2013). We also used an alternative second calibration, using the Eskov and Zonstein (1990) fossils Ambiortiphagus and Cretacattyma to set the minimum age for the most recent common ancestor of Atypidae <> Antrodiaetidae at 100 MYA. 3) minimum age for the root node of Avicularioidea $=$ 216 MYA, based on Edwa (Raven, Jell \& Knezour, 2015), a likely early-diverging avicularioid. For all three calibrations we used a maximum age of 390 MYA, corresponding to the age of fossil Uraraneida, the putative sister group of spiders (Selden, Shear \& Sutton, 2008). This approximate age is in accord with maximum dates derived from other molecular clock analyses of spiders (Ayoub et al. 2007; Wood et al. 2012; Starrett et al. 2013; Fernández et al. 2018; Opatova et al. 2019).

\section{Results}

Voucher data, input DNA values, assembled contig numbers, and UCE locus numbers are found in Table S1. Except for museum samples of Mecicobothrium, all samples returned multiple 100s of loci for all matrices. We highlight Mecicobothrium although we are confident in the results presented here (based on identical placement across all analyses), future studies with fresh specimens should verify the phylogenetic placement discussed below. Raw reads from fifteen original samples have been submitted to the SRA (SAMN10839235 - 10839249).

Annotation of the $\sim 700$ loci derived from the PHYLUCE pipeline indicates that spider UCEs are primary exonic in origin, as essentially all (>98\%) alignments BLAST to proteins found in Stegodyphus and Parasteatoda spiders, with relatively high BIT scores (Tables S2, S3). We note that Stegodyphus and Parasteatoda are true spiders in the clade sister to mygalomorphs; we did not conduct custom BLAST searches against mygalomorphs, as the only sequenced genome (Acanthoscurria) is low coverage and incomplete (Sanggaard et al. 2014). Even the handful of UCE loci without BLAST hits contained open reading frames of variable length, and these could represent proteins that are particularly divergent from araneomorphs, or restricted to mygalomorphs.

We found that 112 total alignments mapped to the same 74 proteins (i.e., different alignments hit same protein; Tables S2, S3). We confirmed that the conserved regions of these separate alignments represented different exons of typically large proteins, and that these exons are likely separated by very long introns (using the known short exon- long intron structure of spiders as models, see Sanggaard et al. 2014). BLAST and visual assessment of the $70 \%$ PHYLUCE matrices indicated that 106 alignments included non-orthologous sequences, and this was confirmed via RAXML analysis of these individual alignments (.tre files in Data S1). Non-orthology was also indicated by annotation, as most alignments including "paralogs" hit two or more different proteins at similar BIT score values (Table S2). The issue of nonorthology is further discussed below. The final matrices were populated as follows: 1) PHYLUCE unfiltered 70\% occupancy (698 loci, 191855 basepairs), 2) $70 \%$ filtered exon

Peer) reviewing PDF | (2019:01:34648:1:2:NEW 25 Mar 2019) 
288

289

290

291

292

293

294

295

296

297

298

299

300

301

302

303

304

305

306

307

308

309

310

311

312

313

314

315

316

317

318

319

320

321

322

323

324

325

326

327

328

329

330

331

332

333

+ intron (480 loci, 137170 basepairs), 3) 70\% filtered exon only (480 loci, 71483 basepairs). All aligned matrices and .tre files are available in Data S1.

Except for one node, all nine phylogenomic analyses recover an identical branching topology within Atypoidea, albeit with variation in branch lengths and node support (Fig. 3). The single node in question involves the interrelationships of Antrodiaetus riversi, $A$. gertschi, and $A$. hadros, all previously in the synonymized genus Atypoides. Overall, the following pertinent clades were recovered with high support (bootstrap > 95 and posterior probability > 0.95) in all analyses: Avicularioidea, Atypoidea, Atypidae, and all genera with multiple sampled species. The fragmentation of mecicobothriids into four separate lineages is strongly supported, with the genus Hexura nested within Antrodiaetidae. The three known species in the synonymized genus Atypoides form a clade sister to "traditional" Antrodiaetus species (Fig. 3), consistent with the well-supported 4-gene results of Hendrixson \& Bond (2009, figs. 1, 2). Results of character evolution and divergence time analyses are presented and discussed below.

\section{Discussion}

Arachnid UCEs. We discovered that the arachnid bait set targets and recovers mostly exons, as suggested by Bossert and Danforth (2018) for arthropod UCE baits in general (see also Branstetter et al. 2017 and Bossert et al. 2018 for hymenopterans). As such, arachnid UCE work is essentially exon capture, with flanking introns also captured for some loci. This of course has important implications for data analysis, because as we have shown here, this functional information can be used to refine analyses is various ways. Our finding also means that it might be possible to extract UCE loci from large spider / arachnid transcriptome datasets (e.g., Sharma et al. 2015; Garrison et al. 2016; Fernández et al. 2018), particularly at deeper phylogenetic levels where exon-only data would provide sufficient signal. Such a combined strategy was recently used in bee phylogenomics (Bossert et al. 2018).

Obviously, orthology is a fundamental premise in phylogenetic analyses. We found that the PHYLUCE unfiltered matrix included alignments with non-orthologs, confirmed via RAXML analysis. This "paralogy" persisted despite bioinformatic filters in place at both probe design (Faircloth, 2017) and PHYLUCE pipeline (Faircloth, 2016) stages. Our findings should not be taken as a criticism of these filters, because initial probedesign does not guarantee perfect orthology (Faircloth, 2017), and because we matched contigs to probes at liberal values (minimum coverage and minimum identity values of 65 ). Here we anticipated a tradeoff, as increasing this value would likely decrease non-orthology, but at the same time reduce the number of returned loci. Part of the issue is that the arachnid bait set was designed for sequence capture across all arachnids (Faircloth, 2017; Starrett et al. 2017), with a common ancestor that likely lived over 500 MYA (e.g., Rota-Stabelli, Daley \& Pisani, 2013). Of all available UCE bait sets (e.g., amniotes, fish, various insects), this represents the greatest phylogenetic depth - the design of more taxon-specific bait sets within 
334 Arachnida, in combination with more stringent probe matching values is expected to

335

336

337

338

339

340

341

342

343

344

345

346

347

348

349

350

351

352

353

354

355

356

357

358

359

360

361

362

363

364

365

366

367

368

369

370

371

372

373

374

375

376

377

378 largely (but probably not entirely) alleviate issues with non-orthology.

Empirical studies have shown that large phylogenomic datasets can be misled even when a minute fraction of loci include non-orthologs (e.g., Brown \& Thomson, 2017; Gatesy et al. 2018). Here analysis of the PHYLUCE unfiltered matrix (with most characters but also non-orthologs) returned trees with the same branching topology within Atypoidea as for filtered matrices (Fig. 3). However, these trees vary somewhat in branch support (Fig. 3), but importantly produce maximum likelihood topologies that differ conspicuously in estimated branch lengths (measured in nucleotide substitutions per nucleotide site). For example, estimated IQ-TREE branch lengths derived from the PHYLUCE unfiltered matrix are 1.5-3X longer than those estimated from the $70 \%$ filtered exon + intron matrix (Fig. S1), with both matrices produced using the same GBLOCKS settings. Exon-only trees have even shorter branch lengths (.tre files in Data S1), but this comparison is confounded by removal of a different class of data (faster-evolving intron sites). To the extent that branch lengths influence downstream inferences (e.g., estimates of divergence times, lineagethrough-time analyses, etc.), these differences in matrix filtering could have potential analytical impacts.

We discovered that some UCE loci treated as separate alignments actually represent exons of the same protein. Via annotation, we confirmed that the conserved regions of these separate alignments represented different exons of typically very large proteins. Although unknown for the taxa studied here, these exons are likely separated by very long introns (using the known short exon- long intron structure of spiders as models, Sanggaard et al. 2014). Inclusion of "duplicate" loci should not negatively impact concatenated phylogenomic analyses. But if the exons represent a single recombinational unit, then treating duplicate alignments as independent would violate analytical assumptions of coalescent-based analyses. Also, for populationlevel analyses relying upon SNPs from UCE loci (e.g., Derkarabetian et al. 2018b), many commonly-used downstream analyses assume no linkage and inclusion of duplicate loci would not be justified.

To summarize, we used custom annotation and manual checking of alignments to show that 1) core regions of arachnid UCEs represent exons, 2) non-orthology sometimes persists in UCE alignments, despite upstream bioinformatic filters, 3) some "separate" loci in the arachnid bait set represent different exons of the same protein (although separated by introns of unknown length). We argue that manual checking of alignments derived from an analytical pipeline remains important (see also Bossert et al. 2018 for another UCE example). Table S3 summarizes which UCE loci have been recovered in arachnid studies to date, and whether these loci are duplicates or potentially non-orthologous. This summary information could be used to further refine UCE analyses in arachnids, e.g., to manually adjust the published bait set to remove duplicates and paralogous loci, where non-orthology is unlikely to be rectified with more stringent probe match values. As has happened for almost all 
379 other UCE bait sets, the refinement of the arachnid set is an expected and natural 380 outcome of knowledge gained through empirical study.

381

382

383

384

385

386

387

388

389

390

391

392

393

394

395

396

397

398

399

400

401

402

403

404

405

406

407

408

409

410

411

412

413

414

415

416

417

418

419

420

421

422

423

424
Atypoid Phylogeny. We found strong support for the monophyly of Atypoidea (following Simon, 1892), based on a molecular phylogenetic sample with all described living genera. Our sample included the key genera Hexurella and Mecicobothrium, never previously sampled in a molecular phylogenetic analysis, and also included multiple early-diverging lineages from Avicularioidea (Hedin et al. 2018a, Opatova et al. 2019). The Atypoidea hypothesis was championed early (Chamberlin \& Ivie, 1945; Coyle 1971; Coyle 1974) but ultimately fell out of favor as putative synapomorphies for the group were interpreted as plesiomorphies (Platnick, 1977; Gertsch \& Platnick, 1979), and the original cladistic morphological analyses for mygalomorphs failed to recover this clade (Raven, 1985; Goloboff, 1993). However, at approximately the same time, Eskov and Zonstein (1990) argued for atypoid monophyly, and these ideas were later supported by early Sanger-based research (Hedin \& Bond, 2006; Bond et al. 2012), although these molecular studies never included all described genera.

The presumed monophyly and placement of mecicobothriids is key in arguments regarding atypoid monophyly. Similar to early-diverging "diplurid" mygalomorphs, living mecicobothriid genera use elongate lateral spinnerets to build silken funnel-andsheet webs. Platnick (1977) considered mecicobothriids to be more closely related to "diplurids" than to atypids or antrodiaetids, although he only examined Megahexura and Hexura. Similarly, Goloboff (1993) recovered mecicobothriids (scored as a single terminal) in an early-diverging grade with "diplurids", but moving the root placement in his preferred phylogeny by one branch recovers atypoid monophyly. In this sense, both the exposed polyphyly of mecicobothriids (see below), and the phylogenomic placement of Hexurella and Mecicobothrium as ancient, early-diverging atypoids that closely straddle the primary division in mygalomorphs (Fig. 3), become centrally important in helping to understand past arguments over morphological homology and polarity. Proposed morphological polarities and diagnostic characters for all primary atypoid lineages are discussed below in the Taxonomy section.

Our phylogenomic results for all described meciobothriid genera convincingly confirm the non-monophyly of this family (Fig. 3). This result is consistent with prior molecular phylogenetic analyses that included Megahexura and Hexura, never recovered as sister taxa (Fig. 2). Mecicobothriid genera are actually morphologically heterogeneous, with each living genus displaying morphological apomorphies in somatic and genital morphology, particularly in female spermathecal morphology (see Gertsch \& Platnick, 1979, Eskov \& Zonsthen1990, see below). Non-monophyly and ancient divergences also help to explain the vexing biogeographic disjunction (Hexurella, Hexura, Megahexura from the western US; Mecicobothrium from southern South America) observed for included genera. Both fossil-calibrated molecular clock estimates indicate that Hexurella and Mecicobothrium stem lineages were likely present during the Triassic, well before the fragmentation of Pangea (Fig. 4, Fig. S2). 
425 Cryptic Species, Webs, Parallel Diversification - Many mygalomorph genera are

426 relatively ancient, morphologically conserved, and dispersal-limited, traits which lead

427 to cryptic speciation. Cryptic species are common in mygalomorphs (e.g., Bond et al.

428 2001; Castalanelli et al. 2014; Leavitt et al. 2015), and found in the atypoids that have

429 been examined closely, antrodiaetids in particular (Hendrixson \& Bond 2007; Satler et

430 al. 2011; Starrett et al. 2018). For example, the single described species Antrodiaetus

431 riversi from central California is actually a complex of multiple cryptic species (Hedin,

432 Starrett \& Hayashi, 2013). Based on relative branch lengths recovered in

433 phylogenomic analyses (Fig. 3), and estimated Cretaceous / early Tertiary ages for

434 genera (Fig. 4, Fig. S2) we predict that cryptic species also occur in the Californian

435 Megahexura, in Hexurella, and in Hexura from Oregon. Hexura is interesting in that

436 the two described parapatric species are apparently ancient, perhaps similar to

437 patterns seen in Ensatina oregonensis / picta salamanders from the rich mesic forests

438 of Oregon (e.g., Kuchta et al. 2009).

439

440

441

442

443

444

445

446

447

448

449

450

451

452

453

454

455

456

457

458

459

460

461

462

463

464

465

466

467

468

469

Character reconstructions indicate rather unambiguously that the ancestral entrance web construct for Atypoidea is a funnel-and-sheet web (Fig. 5), with multiple entrance types derived from this state. Trapdoors in the antrodiaetid genus Aliatypus may have evolved directly from funnel-and-sheet webs, rather than from collapsible collars (contra Coyle, 1971). The well-supported placement of Hexura inside Antrodiaetidae (Fig. 3), as also found in the phylogenomic results of Opatova et al. (2019), is key in this character evolution inference.

We also reconstructed a funnel-and-sheet web as the ancestral state for all mygalomorphs (Fig. 5). Our sample for avicularioids is small, but importantly, includes all key early-diverging lineages (Bond et al. 2012; Hedin et al. 2018a; Opatova et al. 2019). Using a much more comprehensive taxon sample, Opatova et al. (2019) also reconstruct the ancestral web for avicularioids as a funnel-and-sheet web. Many authors have discussed mecicobothriid and "diplurid" web similarities as an example of convergence, for example Gertsch (1949) stated that "the hind spinnerets of these spiders are greatly elongated .... probably an adaptation for spinning the sheet web, ... illustrates how in widely unrelated creatures similar activities often lead to the production of similar morphological features". Instead, our phylogenomic results indicate that the funnel-and-sheet, and elongate lateral spinnerets used to produce these webs, is likely the plesiomorphic condition in mygalomorphs. One caveat is that our funnel-and-sheet scoring may be an over-simplification of homology for these taxa. For example, many early-diverging "diplurids" build massive sheet-like space webs that serve to capture prey (Coyle, 1986), features not obviously present in earlydiverging atypoid webs.

Atypoid Taxonomy - Here we summarize the revised taxonomy of Atypoidea and all included families, focusing on extant taxa (summarized in Fig. 6). The composition of the family Mecicobothriidae is revised. Megahexura and Hexurella are removed from Mecicobothriidae and each included in new families, while Hexura is transferred to the family Antrodiaetidae. Also within Antrodiaetidae, the genus Atypoides is formally 
470 removed from synonymy with Antrodiaetus. All nomenclatural changes proposed are to

471

472

473

474

475

476

477

478

479

480

481

482

483

484

485

486

487

488

489

490

491

492

493

494

495

496

497

498

499

500

501

502

503

504

505

506

507

508

509

510

511

512

513

514

515

be attributed to Hedin and Bond.

The electronic version of this article in Portable Document Format (PDF) will represent a published work according to the International Commission on Zoological Nomenclature (ICZN), and hence the new names contained in the electronic version are effectively published under that Code from the electronic edition alone. This published work and the nomenclatural acts it contains have been registered in ZooBank, the online registration system for the ICZN. The ZooBank LSIDs (Life Science Identifiers) can be resolved and the associated information viewed through any standard web browser by appending the LSID to the prefix http://zoobank.org/. The LSID for this publication is: urn:Isid:zoobank.org:pub:A7E6FD73-9D49-4B55-911F-5D105B09A52C. The online version of this work is archived and available from the following digital repositories: PeerJ, PubMed Central and CLOCKSS."

Family Hexurellidae (NEW FAMILY) (urn:Isid:zoobank.org:act:504C322E-8FAC-4E25806C-DCE37372112E)

Type genus. Hexurella Gertsch \& Platnick, 1979 (urn:Isid:nmbe.ch:spidergen:00010) (type species H. pinea Gertsch \& Platnick, 1979)

Diagnosis. As a consequence of its monogeneric status, characters used to diagnose Hexurellidae are those characters also attributed to the type genus Hexurella, as follows: 1) males having a gently coiled embolus (not corkscrew shaped (illustrated by Gertsch \& Platnick, 1979, figures 77, 84, 87, 90); 2) posterior lateral spinnerets with four segments; and 3) spermathecae composed of a single bursal opening branching into four short, and relatively thicker bulbs (Gertsch \& Platnick, 1979, figure 79). Conversely, megahexurid taxa appear to have much thinner spermathecal bulbs in which pairs share a bursal opening. As is the case for other new taxa and ranks proposed below, a more thorough examination of this new family's morphology will be an important next step in diagnosing these groups.

Distribution. Distributed in upland habitats of southern California, northern Baja California, and central/southern Arizona (Gertsch \& Platnick, 1979). Undescribed species likely occur in the mountains of northern Sonora, Mexico.

Family Mecicobothriidae Holmberg, 1882 (urn:Isid:nmbe.ch:spiderfam:0003) (new circumscription)

Type genus. Mecicobothrium Holmberg , 1882 (urn:Isid:nmbe.ch:spidergen:00011) (type species Mecicobothrium thorelli Holmberg, 1882)

Diagnosis. Characters used to diagnose the family are those characters attributed to the type genus. Adult males of described species have a long and distinctly coiled corkscrew-shaped palpal embolus (e.g., Gertsch \& Platnick, 1979, figures 45, 48, 49; Lucas et al. 2006 figures 1-3) that distinguishes members of this family from all other

Peer) reviewing PDF | (2019:01:34648:1:2:NEW 25 Mar 2019) 
516 atypoid taxa. Males also have a unique anterior cheliceral apophysis (Gertsch \&

517 Platnick, 1979, figures 40-42; Lucas et al. 2006 figures 20-21). Females have distinct

518 spermathecal bulbs comprising four receptacles with the outer pair much shorter and

519 rounder than the inner two (Gertsch \& Platnick, 1979, figure 38); we note that females

520 of $M$. baccai are unknown.

521

522

523

524

525

526

527

528

529

530

531

532

533

534

535

536

537

538

539

540

541

542

543

544

545

Distribution. The two described species are known from Argentina, Uruguay, and Brazil.

Family Megahexuridae (NEW FAMILY) (urn:Isid:zoobank.org:act:0D009AAF-B71C4FFA-A580-DCD67BAA48AB)

Type genus. Megahexura Kaston, 1972 (urn:Isid:nmbe.ch:spidergen:00012) (type species Hexura fulva Chamberlin, 1919)

Diagnosis. Characters used to diagnose the family Megahexuridae are those attributed to the type genus. Members of this family can be diagnosed from other atypoid taxa by having a carapace with expanded pleurites at the posterior lateral corners (Gertsch \& Platnick, 1979, figures 51,53). Megahexurid females have spermathecae with four thin elongate bulbs, with a single receptacle opening for each pair (Gertsch \& Platnick, 1979, figure 57).

Distribution. The single described species (M. fulva) is known from upland habitats of southern and central California (Gertsch \& Platnick, 1979), although populations likely occur in northern Baja California. Megahexura fulva likely includes cryptic species (Fig. 4, Fig. S2).

Family Antrodiaetidae Gertsch,1940 (urn:Isid:nmbe.ch:spiderfam:0002) (new circumscription)

Type genus. Antrodiaetus Ausserer, 1871 (urn:Isid:nmbe.ch:spidergen:00007) (type species Antrodiaetus unicolor (Hentz, 1842))

List of included genera.

Aliatypus Smith, 1908 (urn:Isid:nmbe.ch:spidergen:00006)

Antrodiaetus Ausserer, 1871 (urn:Isid:nmbe.ch:spidergen:00007)

Hexura Simon, 1884 (urn:Isid:nmbe.ch:spidergen:00009)

Atypoides O. Pickard-Cambridge, 1883. (type species Atypoides riversi O. PickardCambridge, 1883 by monotypy). Here formally removed from synonymy of Antrodiaetus Ausserer, 1871 contra Hendrixson and Bond 2007: 752.

List of included species.

Atypoides riversi O. Pickard-Cambridge, 1883

Atypoides hadros Coyle 1968

Atypoides gertschi Coyle 1968 
562 Diagnosis. Adult male antrodiaetids possess a palpal bulb with a branched conductor,

563

564

565

566

567

568

569

570

571

572

573

574

575

576

577

578

579

580

581

582

583

584

585

586

587

588

589

590

591

592

593

594

595

596

597

598

599

600

601

602

603

604

605

606

607

with inner and outer conductor sclerites (following Coyle, 1971, figure 325). The possession of this character state in Hexura was noted in the addendum of Eskov and Zonstein (1990), based on observations of Dr. F. Coyle, and confirmed by our study of male Hexura specimens.

Following Coyle (1968), the genus Atypoides can be distinguished from Antrodiaetus in having three pairs of spinnerets (Coyle, 1968, figures 30-32), with adult males possessing cheliceral apophyses (Coyle, 1968, figures 46-52). Many features separate Atypoides and Antrodiaetus from Hexura and Aliatypus.

Distribution. Aliatypus and Hexura are known from the western United States (Coyle, 1974; Gertsch \& Platnick, 1979), Atypoides is from the western US and the southern Ozarks (Coyle, 1968; Hedin, Starrett \& Hayashi, 2013), while Antrodiaetus includes species in Japan and more broadly in North America (Coyle, 1971; Hendrixson \& Bond, 2007). Cryptic species are likely in all four genera.

Comments. Although megahexurids are sister to antrodiaetids, we do not place them in the same family for three primary reasons. First, these families share a common ancestor that likely existed over 200 million years ago (Fig. 4). This level of divergence would exceed any intra-familial divergence in described mygalomorph families (see Opatova et al. 2019). Second, these families differ in important diagnostic characters, including female spermathecal morphology, but importantly megahexurid males lack the key antrodiaetid palpal bulb with diagnostic inner and outer conductor sclerites (Fig. 6).

Conversely, one could argue that Aliatypus and Hexura each deserve family-level status (the latter an available family rank name, Hexurinae Simon 1889), sister to other antrodiaetids. Again, although heterogenous from a web construct perspective (Fig. 5), antrodiaetids share morphological synapomorphies, with a level of inter-generic temporal divergence comparable to other described mygalomorph families (Fig. 4, Opatova et al. 2019).

\section{Conclusions}

Early-diverging atypoid lineages are ancient, often species-poor (approximating monotypic), and use silk to build funnel-and-sheet webs. The evolution of more diverse silken entrance constructs is found in more derived atypoid lineages. Similar patterns of species-poor early-diverging lineages, and diverse entrance constructs evolving in more derived lineages occurs in parallel in the avicularioid mygalomorphs (Opatova et al. 2019). In this sense, atypoids and avicularioids represent comparable evolutionary experiments, although the latter clade has clearly evolved a greater diversity of taxa, morphologies, and web constructs. How the competitive interplay of these parallel lineages has impacted diversification dynamics in deep time would be an interesting topic for further study.

\section{Acknowledgements}

Peer) reviewing PDF | (2019:01:34648:1:2:NEW 25 Mar 2019) 
609 We thank Nobuo Tsurusaki, Dean Leavitt, Jordan Satler and in particular Jim Starrett for 610 help with specimen collection. Gabriel Pompozzi provided images of Mecicobothrium. 611 Comments of Brent Hendrixson, D. Leavitt, J. Starrett and an anonymous reviewer 612 helped to improve the manuscript.

613 


\section{References}

615

616

617

618

619

620

621

622

623

624

625

626

627

628

629

630

631

632

633

634

635

636

637

638

639

640

641

642

643

644

645

646

647

648

649

650

651

652

653

654

655

656

657
Ayoub NA, Garb JE, Hedin M, Hayashi CY (2007) Utility of the nuclear protein-coding gene, elongation factor-1 gamma (EF-1Y), for spider systematics, emphasizing family level relationships of tarantulas and their kin (Araneae: Mygalomorphae). Molecular Phylogenetics and Evolution 42, 394-409.

Bejerano G, Pheasant M, Makunin I, Stephen S, Kent WJ, Matttick JS, Haussler D (2004) Ultraconserved elements in the human genome. Science 304, 1321-1325.

Branstetter MG, Longino JT, Ward PS, Faircloth BC (2017) Enriching the ant tree of life: enhanced UCE bait set for genome-scale phylogenetics of ants and other Hymenoptera. Methods in Ecology and Evolution 8, 768-776.

Bond JE, Hedin MC, Ramirez MG, Opell BD (2001) Deep molecular divergence in the absence of morphological and ecological change in the Californian coastal dune endemic trapdoor spider Aptostichus simus. Molecular Ecology 10, 899-910.

Bond JE, Hendrixson BE, Hamilton CA, Hedin M (2012) A reconsideration of the classification of the spider infraorder Mygalomorphae (Arachnida: Araneae) based on three nuclear genes and morphology. PLoS One 7(6), e38753.

Bouckaert R, Heled J, Kühnert D, Vaughan T, Wu C-H, Xie D, Suchard MA, Rambaut A, Drummond AJ (2014). BEAST 2: A Software Platform for Bayesian Evolutionary Analysis. PLoS Computational Biology, 10(4), e1003537.

Borowiec ML (2019) Convergent evolution of the army ant syndrome and congruence in big-data phylogenetics Systematic Biology, In Press.

Bossert S, Danforth BN (2018) On the universality of target-enrichment baits for phylogenomic research. Methods in Ecology and Evolution 00:1-8. doi: 10.1111/2041-210X.12988.

Bossert S, Murray EA, Almeida EAB, Brady SG, Blaimer BB, Danforth BN (2018) Combining transcriptomes and ultraconserved elements to illuminate the phylogeny of Apidae. Molecular Phylogenetics and Evolution https://doi.org/10.1016/j.ympev.2018.10.012.

Brown JM, Thomson RC (2017) Bayes Factors unmask highly variable information content, bias, and extreme influence in phylogenomic analyses. Systematic Biology 66, 517-530.

Castalanelli MA, Teale R, Rix MG, Kennington WJ, Harvey MS (2014) Barcoding of mygalomorph spiders (Araneae: Mygalomorphae) in the Pilbara bioregion of Western Australia reveals a highly diverse biota. Invertebrate Systematics 28, 375-385.

Castresana J (2000) Selection of conserved blocks from multiple alignments for their use in phylogenetic analysis. Molecular Biology Evolution 17, 540-552

Chamberlin RV, Ivie W (1945) On some Nearctic mygalomorph spiders. Annals of the Entomological Society of America 38, 549-558.

Chernomor O, von Haeseler A, Minh BQ (2016) Terrace aware data structure for phylogenomic inference from supermatrices. Systematic Biology 65, 997-1008.

Chifman J, Kubatko L (2014) Quartet inference from SNP data under the coalescent. Bioinformatics 30, 3317-3324. 
658

659

660

661

662

663

664

665

666

667

668

669

670

671

672

673

674

675

676

677

678

679

680

681

682

683

684

685

686

687

688

689

690

691

692

693

694

695

696

697

698

699

700

701

702

703

Chifman J, Kubatko L (2015) Identifiability of the unrooted species tree topology under the coalescent model with time-reversible substitution processes, site-specific rate variation, and invariable sites. Journal of Theoretical Biology 374, 35-47.

Clarke TH, Garb JE, Hayashi CY, Arensburger P, Ayoub NA (2015) Spider transcriptomes identify ancient large-scale gene duplication event potentially important in silk gland evolution. Genome Biology and Evolution 7, 1856-1870.

Costa FG, Pérez-Miles F (1998) Behavior, life cycle and webs of Mecicobothrium thorelli (Araneae, Mygalomorphae, Mecicobothriidae). Journal of Arachnology 26, 317-329.

Coyle FA (1968) The mygalomorph spider genus Atypoides (Araneae: Antrodiaetidae). Psyche, Cambridge 75, 157-194.

Coyle FA (1971) Systematics and natural history of the mygalomorph spider genus Antrodiaetus and related genera (Araneae: Antrodiaetidae). Bulletin of the Museum of Comparative Zoology 141, 269-402.

Coyle FA (1974) Systematics of the trapdoor spider genus Aliatypus (Araneae: Antrodiaetidae). Psyche, Cambridge 81, 431-500.

Coyle FA (1986) The role of silk in prey capture by nonaraneomorph spiders. In: Shear WA, ed. Spiders: Webs, Behavior, and Evolution. Stanford University Press. 269305.

Dalla Vecchia FM, Selden PA (2013) A Triassic spider from Italy. Acta Palaeontologica Polonica 58, 325-330.

Derkarabetian S, Starrett J, Tsurusaki N, Ubick D, Castillo S, Hedin M (2018a) A stable phylogenomic classification of Travunioidea (Arachnida, Opiliones, Laniatores) based on sequence capture of ultraconserved elements. ZooKeys (760), 1-36.

Derkarabetian S, Castillo S, Koo PK, Ovchinnikov S, Hedin M (2018b). An empirical demonstration of unsupervised machine learning in species delimitation. bioRxiv doi: https://doi.org/10.1101/429662.

Eskov KY, Zonstein S (1990) First Mesozoic mygalomorph spiders from the Lower Cretaceous of Siberia and Mongolia, with notes on the system and evolution of the infraorder Mygalomorphae (Chelicerata: Araneae). Neues Jahrbuch für Mineralogie, Geologie und Paläontologie, Abhandlungen 178, 325-368.

Faircloth BC (2013) illumiprocessor: a trimmomatic wrapper for parallel adapter and quality trimming. http://dx.doi.org/10.6079/J9ILL

Faircloth BC (2016) PHYLUCE is a software package for the analysis of conserved genomic loci. Bioinformatics 32, 786-788.

Faircloth BC (2017) Identifying conserved genomic elements and designing universal probe sets to enrich them. Methods in Ecology and Evolution 8, 1103-1112.

Faircloth BC, McCormack JE, Crawford NG, Harvey MG, Brumfield RT, Glenn TC (2012) Ultraconserved elements anchor thousands of genetic markers spanning multiple evolutionary timescales. Systematic Biology 61, 717-726.

Faircloth BC, Branstetter MG, White ND, Brady SG (2015) Target enrichment of ultraconserved elements from arthropods provides a genomic perspective on relationships among Hymenoptera. Molecular Ecology Resources 15, 489-501.

Fernández R, Kallal RJ, Dimitrov D, Ballesteros JA, Arnedo MA, Giribet G, Hormiga G (2018) Phylogenomics, diversification dynamics, and comparative transcriptomics across the Spider Tree of Life. Current Biology 28, 1489-1497.e5 
704 Fourie R, Haddad CR, Jocqué R (2011). A revision of the purse-web spider genus

705

706

707

708

709

710

711

712

713

714

715

716

717

718

719

720

721

722

723

724

725

726

727

728

729

730

731

732

733

734

735

736

737

738

739

740

741

742

743

744

745

746

747

748

749

Calommata Lucas, 1837 (Araneae, Atypidae) in the Afrotropical region. ZooKeys

95, 1-28.

Garrison NL, Rodriguez J, Agnarsson I, Coddington JA, Griswold CE, Hamilton CA, Hedin M, Kocot KM, Ledford JM, Bond JE (2016) Spider Phylogenomics:

Untangling the Spider Tree of Life. PeerJ 4:e1719; DOI 10.7717/peerj.1719.

Gatesy J, Sloan DB, Warren JM, Baker RH, Simmons MP, Springer MS (2018)

Partitioned coalescence support reveals biases in species-tree methods and detects gene trees that determine phylogenomic conflicts. bioRxiv doi:

http://dx.doi.org/10.1101/461699.

Gertsch WJ (1949) American Spiders. D. van Nostrand, New York.

Gertsch WJ, Platnick NI (1979) A revision of the spider family Mecicobothriidae

(Araneae, Mygalomorphae). American Museum Novitates 2687, 1-32.

Goloboff P (1993) A reanalysis of mygalomorph spider families (Araneae). American Museum Novitates 3056, 1-32

Grabherr MG, Haas BJ, Yassour M, Levin JZ, Thompson DA, Amit I, Adiconis X, Fan L, Raychowdhury R, Zeng Q, Chen Z (2011) Full-length transcriptome assembly from RNA-Seq data without a reference genome. Nature Biotechnology 29, 644.

Hamilton CA, Lemmon AR, Lemmon EM, Bond JE (2016) Expanding anchored hybrid enrichment to resolve both deep and shallow relationships within the spider tree of life. BMC Evolutionary Biology 16, 212.

Hedin M, Bond JE (2006) Molecular phylogenetics of the spider infraorder Mygalomorphae using nuclear rRNA genes (18S and 28S): Conflict and agreement with the current system of classification. Molecular Phylogenetics and Evolution 41, 454-471.

Hedin M, Starrett J, Hayashi C (2013) Crossing the uncrossable: novel trans-valley biogeographic patterns revealed in the genetic history of low-dispersal mygalomorph spiders (Antrodiaetidae, Antrodiaetus) from California. Molecular Ecology 22, 508-526.

Hedin M, Derkarabetian S, Ramírez M, Vink C, Bond J (2018a) Phylogenomic reclassification of the world's most venomous spiders (Mygalomorphae, Atracinae), with implications for venom evolution. Scientific Reports 8, 1636 D.

Hedin M, Derkarabetian S, Blair J, Paquin P (2018b) Sequence capture phylogenomics of eyeless Cicurina spiders from Texas caves, with emphasis on US federallyendangered species from Bexar County (Araneae, Hahniidae). ZooKeys 769, 4976.

Hendrixson BE, Bond JE (2007) Molecular phylogeny and biogeography of an ancient Holarctic lineage of mygalomorph spiders (Araneae: Antrodiaetidae: Antrodiaetus). Molecular Phylogenetics and Evolution 42, 738-755.

Hendrixson BE, Bond JE (2009) Evaluating the efficacy of continuous quantitative characters for reconstructing the phylogeny of a morphologically homogeneous spider taxon (Araneae, Mygalomorphae, Antrodiaetidae, Antrodiaetus). Molecular Phylogenetics and Evolution. 53, 300-13.

Hoang DT, Chernomor O, von Haeseler A, Minh BQ, Vinh LS (2018) UFBoot2: Improving the ultrafast bootstrap approximation. Molecular Biology and Evolution $35,518-522$.

Peer) reviewing PDF | (2019:01:34648:1:2:NEW 25 Mar 2019) 
750

751

752

753

754

755

756

757

758

759

760

761

762

763

764

765

766

767

768

769

770

771

772

773

774

775

776

777

778

779

780

781

782

783

784

785

786

787

788

789

790

791

792

793

794

Kalyaanamoorthy S, Minh BQ, Wong TKF, von Haeseler A, Jermiin LS (2017) ModelFinder: Fast model selection for accurate phylogenetic estimates. Nature Methods 14, 587-589.

Katoh D, Standley DM (2013) MAFFT multiple sequence alignment software version 7: improvements in performance and usability. Molecular Biology and Evolution 30, 772-780.

Kieran TJ, Gordon ERL, Forthman M, Hoey-Chamberlain R, Kimball RT, Faircloth BC, Weirauch C, Glenn TC (2018) Insight from an Ultraconserved element bait set designed for Hemipteran phylogenetics integrated with genomic resources. Molecular Phylogenetics and Evolution https://doi.org/10.1016/j.ympev.2018.10.026.

Kuchta SR, Parks DS, Mueller RL, Wake DB (2009) Closing the ring: historical biogeography of the salamander ring species Ensatina eschscholtzii. Journal of Biogeography 36, 982-995.

Lartillot N, Philippe H (2004) A Bayesian mixture model for across-site heterogeneities in the amino-acid replacement process. Molecular Biology and Evolution 21, 10951109.

Leavitt DH, Starrett J, Westphal MF, Hedin M (2015) Multilocus sequence data reveal dozens of putative cryptic species in a radiation of endemic Californian mygalomorph spiders (Araneae, Mygalomorphae, Nemesiidae). Molecular Phylogenetics and Evolution 91, 56-67.

Lewis PO (2001) A likelihood approach to estimating phylogeny from discrete morphological character data. Systematic Biology 50, 913-925.

Lucas SM, Indicatti RP, Brescovit AD Francisco RC (2006) First record of the Mecicobothriidae Holmberg from Brazil, with a description of a new species of Mecicobothrium (Araneae, Mygalomorphae). Zootaxa 1326, 45-53.

Maddison WP, Maddison DR (2018) Mesquite: a modular system for evolutionary analysis. Version $3.51 \mathrm{http}: / / \mathrm{www}$.mesquiteproject.org

McCole RB, Erceg J, Saylor W, Wu C-T (2018) Ultraconserved elements occupy specific arenas of three-dimensional mammalian genome organization. Cell Reports 24, 479-488.

Nguyen L-T, Schmidt HA, von Haeseler A, Minh BQ (2015) IQ-TREE: A fast and effective stochastic algorithm for estimating maximum likelihood phylogenies. Molecular Biology and Evolution 32, 268-274.

Opatova V, Hamilton CA, Hedin M, Montes de Oca L, Král J, Haddad CR, Bond JE (2019) Reevaluation of the systematics and classification of the spider infraorder Mygalomorphae using genomic scale data. bioRxiv doi: https://doi.org/10.1101/531756

Platnick NI (1977) The hypochiloid spiders: a cladistic analysis, with notes on the Atypoidea (Arachnida, Araneae). American Museum Novitates 2627, 1-23.

Polychronopoulos D, King JWD, Nash AJ, Tan G, Lenhard B (2017) Conserved noncoding elements: developmental gene regulation meets genome organization, Nucleic Acids Research 45, 12611-12624.

Raven RJ (1985) The spider infraorder Mygalomorphae (Araneae): Cladistics and systematics. Bulletin American Museum of Natural History 182, 1-180. 
795

796

797

798

799

800

801

802

803

804

805

806

807

808

809

810

811

812

813

814

815

816

817

818

819

820

821

822

823

824

825

826

827

828

829

830

831

832

833

834

835

836

837

838

839

840

Raven RJ, Jell PA, Knezour RA (2015) Edwa maryae gen. et sp. nov. in the Norian Blackstone Formation of the Ipswich Basin-the first Triassic spider

(Mygalomorphae) from Australia. Alcheringa 39, 259-263.

Rota-Stabelli O, Daley AC, Pisani D (2013) Molecular timetrees reveal a Cambrian colonization of land and a new scenario for ecdysozoan evolution. Current Biology 23, 392-8.

Sanggaard KW, Bechsgaard JS, Fang X, Duan J, Dyrlund TF, Gupta V, Jiang X, Cheng L, Fan D, Feng Y, Han L (2014) Spider genomes provide insight into composition and evolution of venom and silk. Nature Communications 5, 3765.

Satler JD, Starrett J, Hayashi CY, Hedin M (2011) Inferring species trees from gene trees in a radiation of California trapdoor spiders (Araneae, Antrodiaetidae, Aliatypus). PLoS One, 6(9) doi:http://dx.doi.org/10.1371/journal.pone.0025355

Schwager EE, Sharma PP, Clarke T, Leite DJ, Wierschin T, Pechmann M, AkiyamaOda Y, Esposito L, Arensburger P, Bechsgaard J, Bilde T, Buffry A, Chao H, Dinh H, Doddapaneni H, Dugan S, Eibner C, Extavour CG, Funch P, Garb J, Gonzalez VL, Griffiths-Jones S, Han Y, Hayashi C, Hilbrant M, Hughes DST, Janssen R, Lee SL, Maeso I, Murali SC, Muzny DM, da Fonseca RN, Qu J, Ronshaugen M, Schomburg C, Schönauer A, Stollewerk A, Torres-Oliva M, Turetzek N, Vanthournout B, Werren J, Wolff C, Worley KC, Gibbs RA, Coddington J, Oda H, Stanke M, Ayoub NA, Damen WGM, Prpic N-M, Flot J-F, Posnien N, Richards S, McGregor AP (2017) The house spider genome reveals a whole genome duplication during arachnid evolution. BMC Biology 15, 62.

Schwendinger PJ (1990) A synopsis of the genus Atypus (Araneae, Atypidae). Zoologica Scripta 19, 353-366.

Selden PA, Gall J-C (1992) A Triassic mygalomorph spider from the northern Vosges, France. Palaeontology 35, 211-235.

Selden PA, Shear WA, Sutton MD (2008) Fossil evidence for the origin of spider spinnerets, and a proposed arachnid order. Proceedings of the National Academy of Sciences of the United States of America 105, 20781-20785.

Sharma PP, Fernández R, Esposito L, González-Santillán E, Monod L (2015) Phylogenomic resolution of scorpions reveals multilevel discordance with morphological phylogenetic signal. Proceedings of the Royal Society of London B: Biological Sciences 282, 20142953.

Simon E (1892) Histoire naturelle des araignées. Paris 1, 1-256.

Stamatakis A (2014) RAxML version 8: a tool for phylogenetic analysis and postanalysis of large phylogenies. Bioinformatics 30, 1312-1313.

Starrett J, Hedin M, Ayoub N, Hayashi CY (2013) Hemocyanin gene family evolution in spiders (Araneae), with implications for phylogenetic relationships and divergence times in the infraorder Mygalomorphae. Gene 524, 175-186.

Starrett J, Derkarabetian S, Hedin M, Bryson Jr. RW, McCormack JE, Faircloth BC.( 2017) High phylogenetic utility of an Ultraconserved element probe set designed for Arachnida. Molecular Ecology Resources 17, 812-823.

Starrett J, Hayashi CY, Derkarabetian S, Hedin M (2018) Cryptic elevational zonation in trapdoor spiders (Araneae, Antrodiaetidae, Aliatypus janus complex) from the California southern Sierra Nevada. Molecular Phylogenetics and Evolution 118, 403-413. 
841 Swofford DL (2003) PAUP*: phylogenetic analysis using parsimony, version 4.0a163.

842 Talavera G, Castresana J (2007) Improvement of phylogenies after removing divergent

843

844

845

846

847

848

849

850

851

852

853

854

855

856

857

858

859

860

861

862

863

864

865

866

867

868

869

870

871

872

873 and ambiguously aligned blocks from protein sequence alignments. Systematic Biology 56, 564-577.

Thorne JL, Kishino H, Painter IS (1998) Estimating the rate of evolution of the rate of molecular evolution. Molecular Biology and Evolution 15, 1647-1657.

Tin MM-Y, Economo EP, Mikheyev AS (2014) Sequencing degraded DNA from nondestructively sampled museum specimens for RAD-Tagging and low-coverage shotgun phylogenetics. PLoS ONE 9, e96793. https://doi.org/10.1371/journal.pone.0096793

Wheeler WC, Coddington JA, Crowley LM, Dimitrov D, Goloboff PA, Griswold CE, Hormiga G, Prendini L, Ramírez MJ, Sierwald P, Almeida-Silva L, Alvarez-Padilla F, Arnedo MA, Benavides Silva LR, Benjamin SP, Bond JE, Grismado CJ, Hasan E, Hedin M, Izquierdo MA, Labarque FM, Ledford J, Lopardo L, Maddison WP, Miller JA, Piacentini LN, Platnick NI, Polotow D, Silva-Dávila D, Scharff N, Szüts T, Ubick D, Vink CJ, Wood HM, Zhang J (2017) The spider tree of life: phylogeny of Araneae based on target-gene analyses from an extensive taxon sampling. Cladistics 33, 574-616. doi:10.1111/cla.12182.

Wood HM, Matzke NJ, Gillespie RG, Griswold CE (2012) Treating fossils as terminal taxa in divergence time estimation reveals ancient vicariance patterns in the palpimanoid spiders. Systematic Biology 62, 264-284.

Wood HM, González VL, Lloyd M, Coddington J, Scharff N (2018) Next-generation museum genomics: Phylogenetic relationships among palpimanoid spiders using sequence capture techniques (Araneae: Palpimanoidea). Molecular Phylogenetics and Evolution 127, 907-918.

World Spider Catalog (2019). World Spider Catalog. Version 20. Natural History Museum Bern, online at http://wsc.nmbe.ch, accessed on 25 Feb 2019. doi: $10.24436 / 2$

Yang Z, Rannala B (2006). Bayesian estimation of species divergence times under a molecular clock using multiple fossil calibrations with soft bounds. Molecular Biology Evolution 23, 212-226.

Zerbino DR, Birney E (2008) Velvet: Algorithms for de novo short read assembly using de Bruijn graphs. Genome Research 18, 821-829.

874 


\section{Figure Legends}

876

877

878

879

880

881

882

883

884

885

886

887

888

889

890

891

892

893

894

895

896

897

898

899

900

901

902

903

904

905

906

907
Figure 1. Images of live animals and entrance web constructs, not to scale. A) Hexurella apachea, Cochise County, AZ. MCH 18_029. B) Mecicobothrium thorelli, image by G. Pompozzi. C) Atypus karschi. Honshu, Tottori, Japan. MCH 15_016. D) Megahexura fulva, Fresno County, CA. MCH 09_018. E) Aliatypus californicus. Contra Costa County, CA. MCH 10_031. F) Hexura picea. Lincoln County, OR. MCH 14_040. G) Antrodiaetus unicolor, Jackson County, NC. H) Atypoides (= Antrodiaetus) riversi, San Mateo County, CA. MCH 10_015. Arrows point to dorsal abdominal tergites in images B, E and G. All photos (other than Mecicobothrium) by M. Hedin.

Figure 2. Summary of previous molecular phylogenetic analyses including members of Atypoidea. References as in text.

Figure 3. Tree topology from RAxML concatenated analysis, based on filtered exon + intron matrix. Support values for all nine analyses either indicated directly, or by circles at nodes (when exceeding 95 or 0.95 for all). Support values within (Namirea, Euagrus, Bymainiella, Calisoga) clade not shown, as these relationships vary across analyses (see .tre files in Data S1). Also, two low support nodes not shown for PHYLUCE unfiltered SVD results, as follows: Antrodiaetus apachecus + A. roretzi (67), Antrodiaetus hadros + A. gertschi (68).

Figure 4. Chronogram derived from Phylobayes analyses, estimated using calibration with minimum age for the root node of Atypoidea $=210 \mathrm{MYA}$. HPD values in brackets. Results using the alternative calibration included as Fig. S2. Geological times from http://www.geosociety.org/documents/gsa/timescale/timescl.pdf.

Figure 5. Ancestral character reconstruction for entrance web constructs. Proportional likelihood values for funnel-and-sheet web shown at internal nodes.

Figure 6. Summary of new taxonomy and diagnostic morphological characters. See text for references and explanation of terms. 


\section{Figure 1}

Images of live animals and entrance web constructs

A) Hexurella apachea, Cochise County, AZ. MCH 18_029. B) Mecicobothrium thorelli, image by G. Pompozzi. C) Atypus karschi. Honshu, Tottori, Japan. MCH 15_016. D) Megahexura fulva, Fresno County, CA. MCH 09_018. E) Aliatypus californicus. Contra Costa County, CA. MCH 10_031. F) Hexura picea. Lincoln County, OR. MCH 14_040. G) Antrodiaetus unicolor, Jackson County, NC. H) Atypoides (= Antrodiaetus) riversi, San Mateo County, CA. MCH 10_015. Arrows point to dorsal abdominal tergites in images B, E and G. All photos (other than Mecicobothrium) by M. Hedin. 

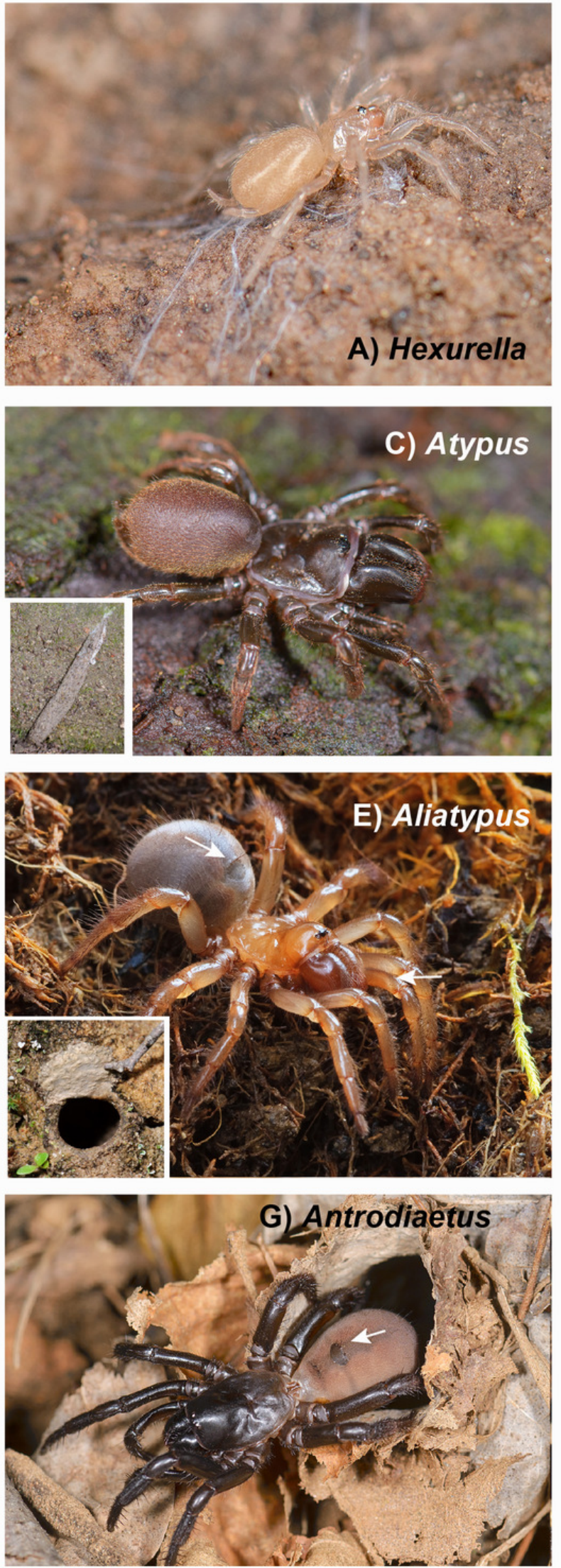
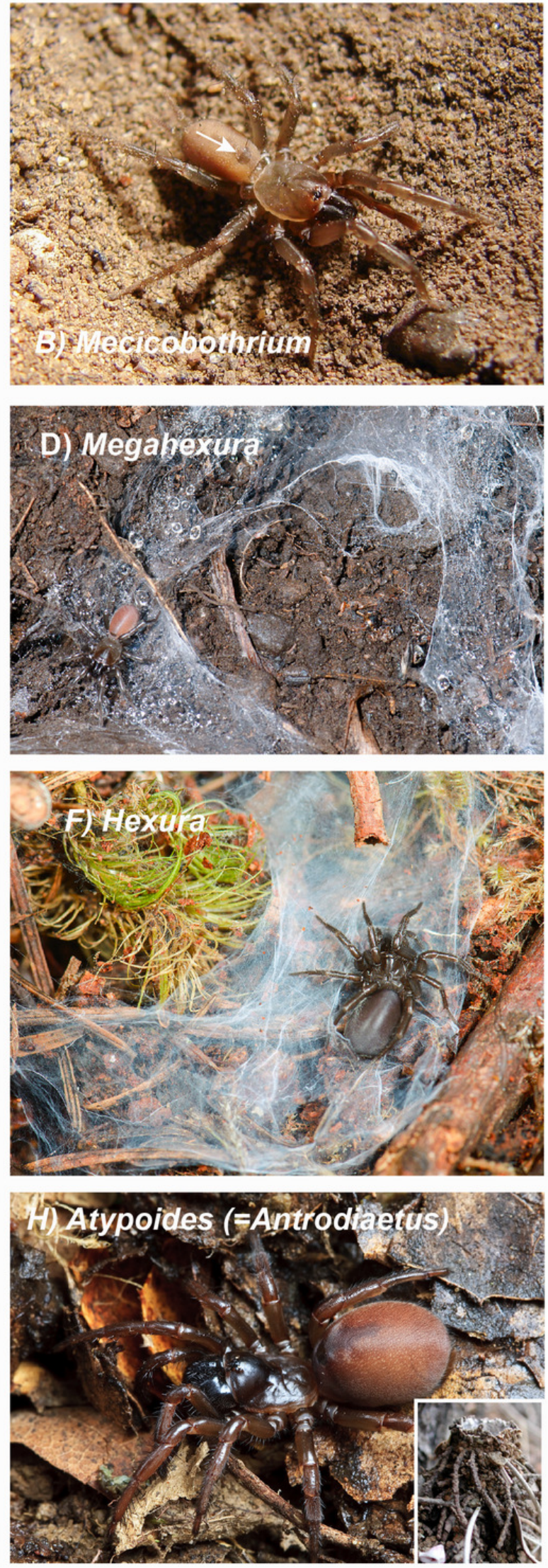
Figure 2 (on next page)

Summary of previous molecular phylogenetic analyses including members of Atypoidea.

References as in text. 
Hedin \& Bond 2006, FIG 5

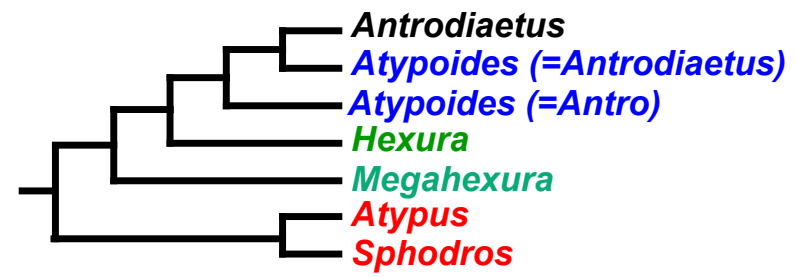

Ayoub et al 2007, FIG 3

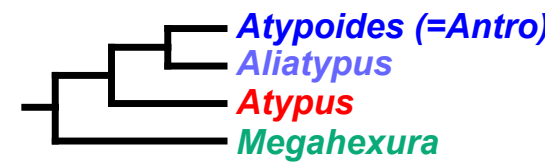

Bond et al 2012, FIG 1

- Antrodiaetus

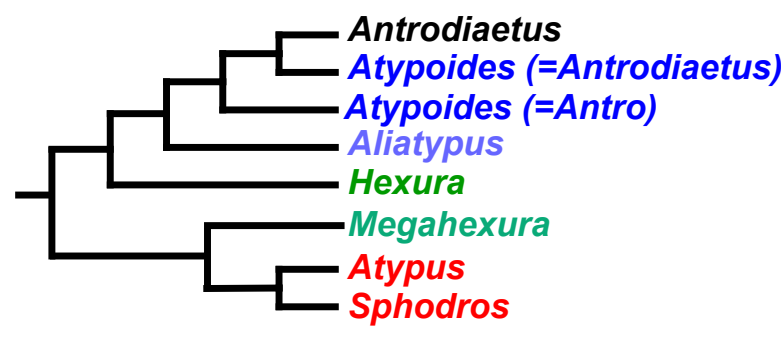

Starrett et al 2013, FIG 5

Atypoides (=Antro)

$\longdiv { \square }$ Aliatypus

Sphodros

Hamilton et al 2016, FIG 4

\section{Antrodiaetus}

$\sqrt{- \text { Hexura }}$

Sphodros

Garrison et al 2016, FIG 2

Antrodiaetus

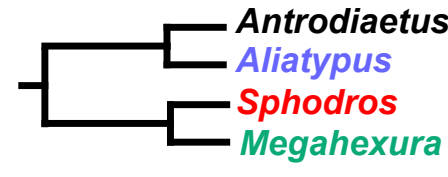

Wheeler et al 2017, FIG 2

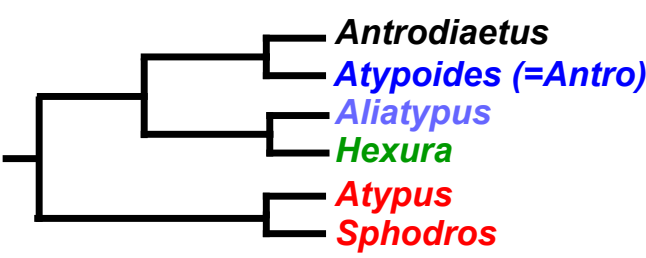

Hedin et al 2018a, FIG 2

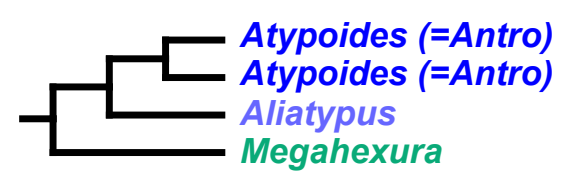

Fernandez et al 2018, FIG 1

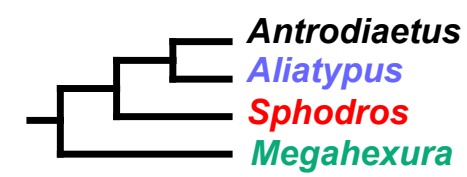

Opatova et al 2019, FIG 3

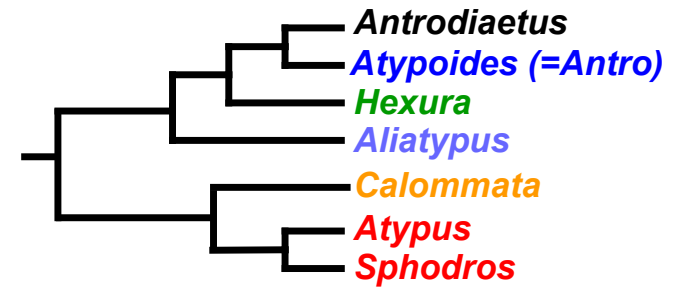


Figure 3 (on next page)

Tree topology from RAxML concatenated analysis, based on filtered exon + intron matrix.

Support values for all nine analyses either indicated directly, or by circles at nodes (when exceeding 95 or 0.95 for all). Support values within (Namirea, Euagrus, Bymainiella, Calisoga) clade not shown, as these relationships vary across analyses (see .tre files in Data S1). Also, two low support nodes not shown for Phyluce unfiltered SVD results, as follows: Antrodiaetus apachecus + A. roretzi (67), Antrodiaetus hadros + A. gertschi (68). 


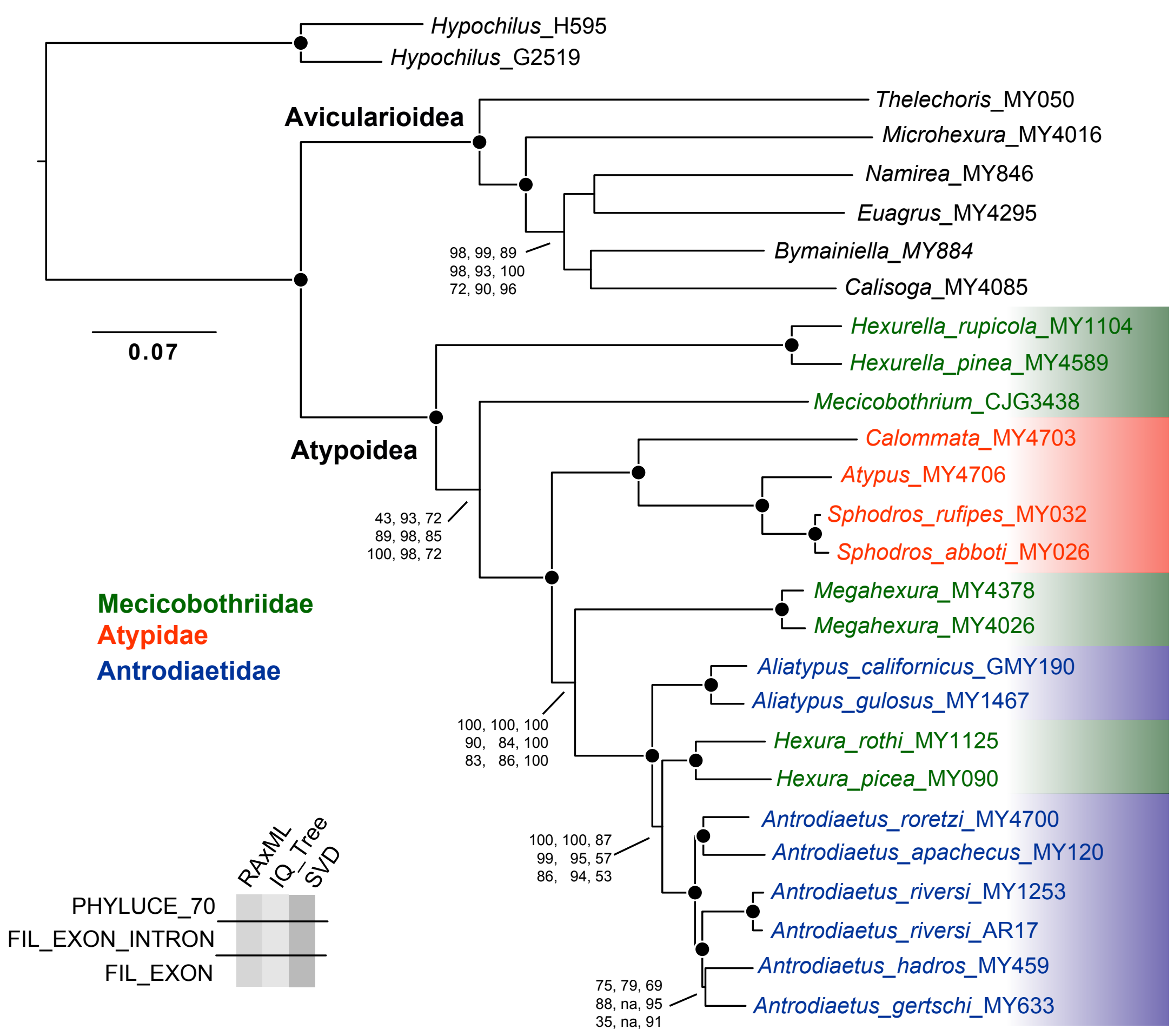


Figure 4 (on next page)

Chronogram derived from Phylobayes analyses, estimated using calibration with minimum age for the root node of Atypoidea $=210$ MYA.

HPD values in brackets. Results using the alternative calibration included as Fig. S2. Geological times from http://www.geosociety.org/documents/gsa/timescale/timescl.pdf . 


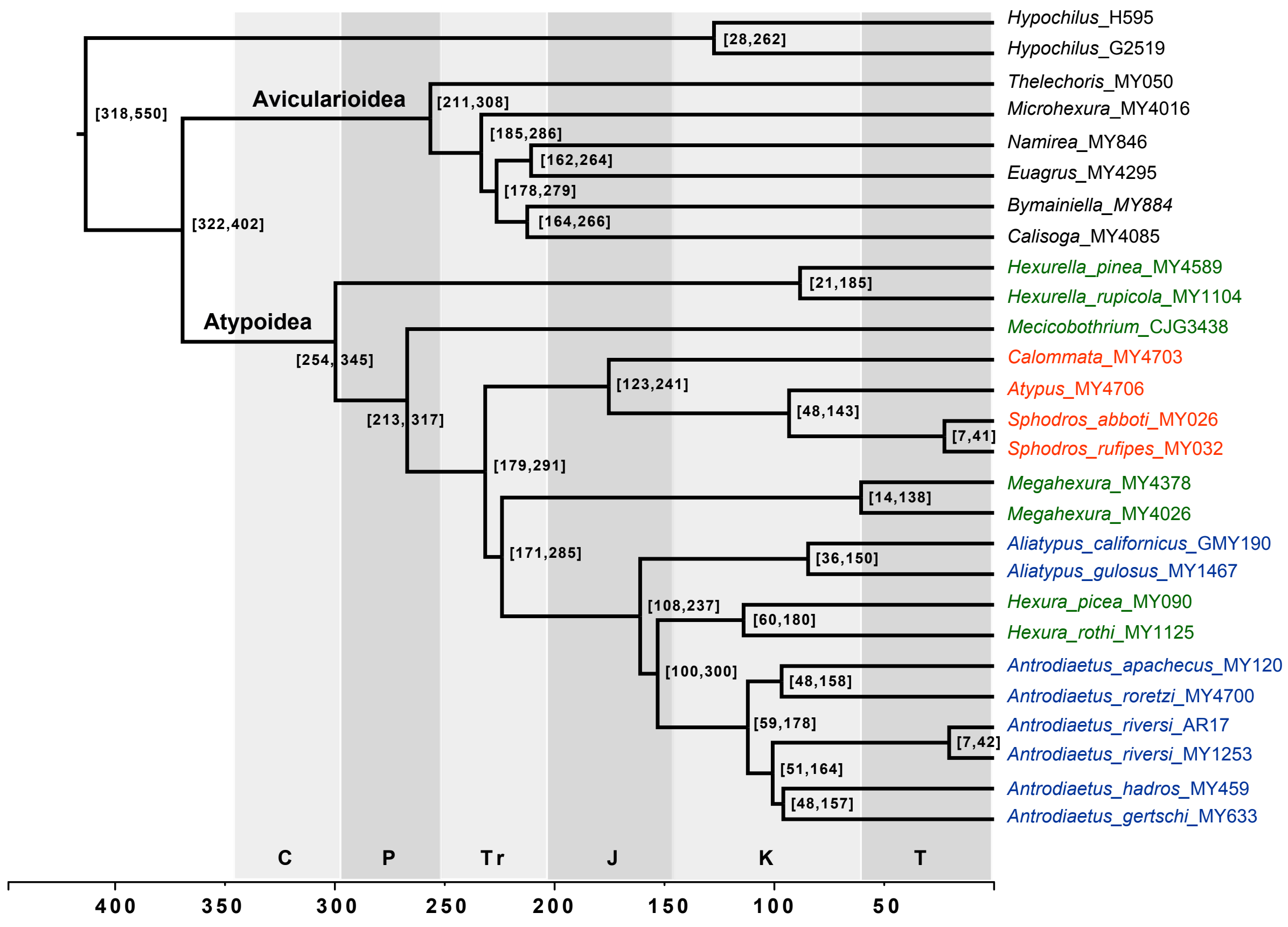


Figure $\mathbf{5}$ (on next page)

Ancestral character reconstruction for entrance web constructs.

Proportional likelihood values for funnel-and-sheet web shown at internal nodes. 


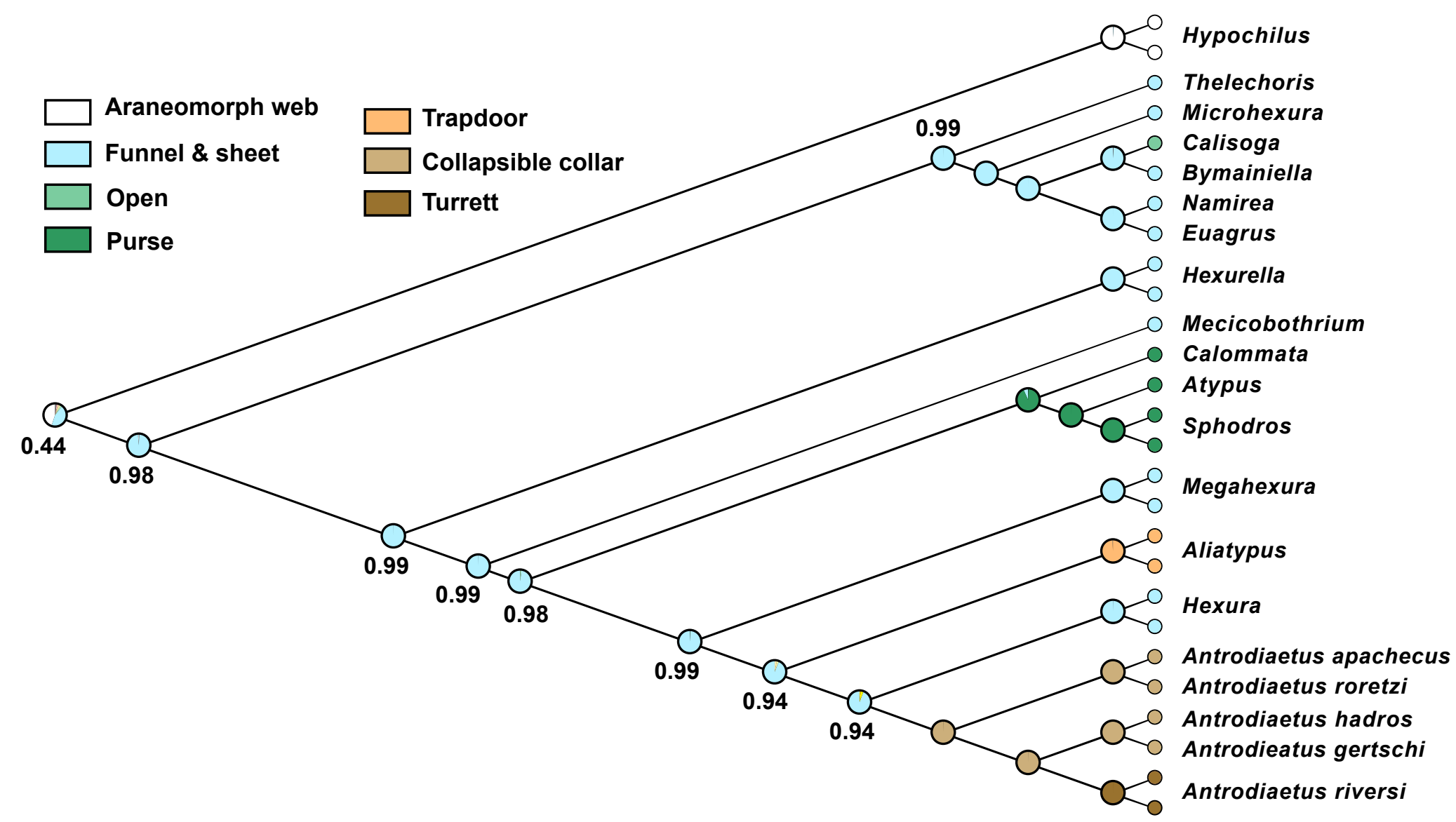


Figure 6 (on next page)

Summary of new taxonomy and diagnostic morphological characters.

See text for references and explanation of terms. 


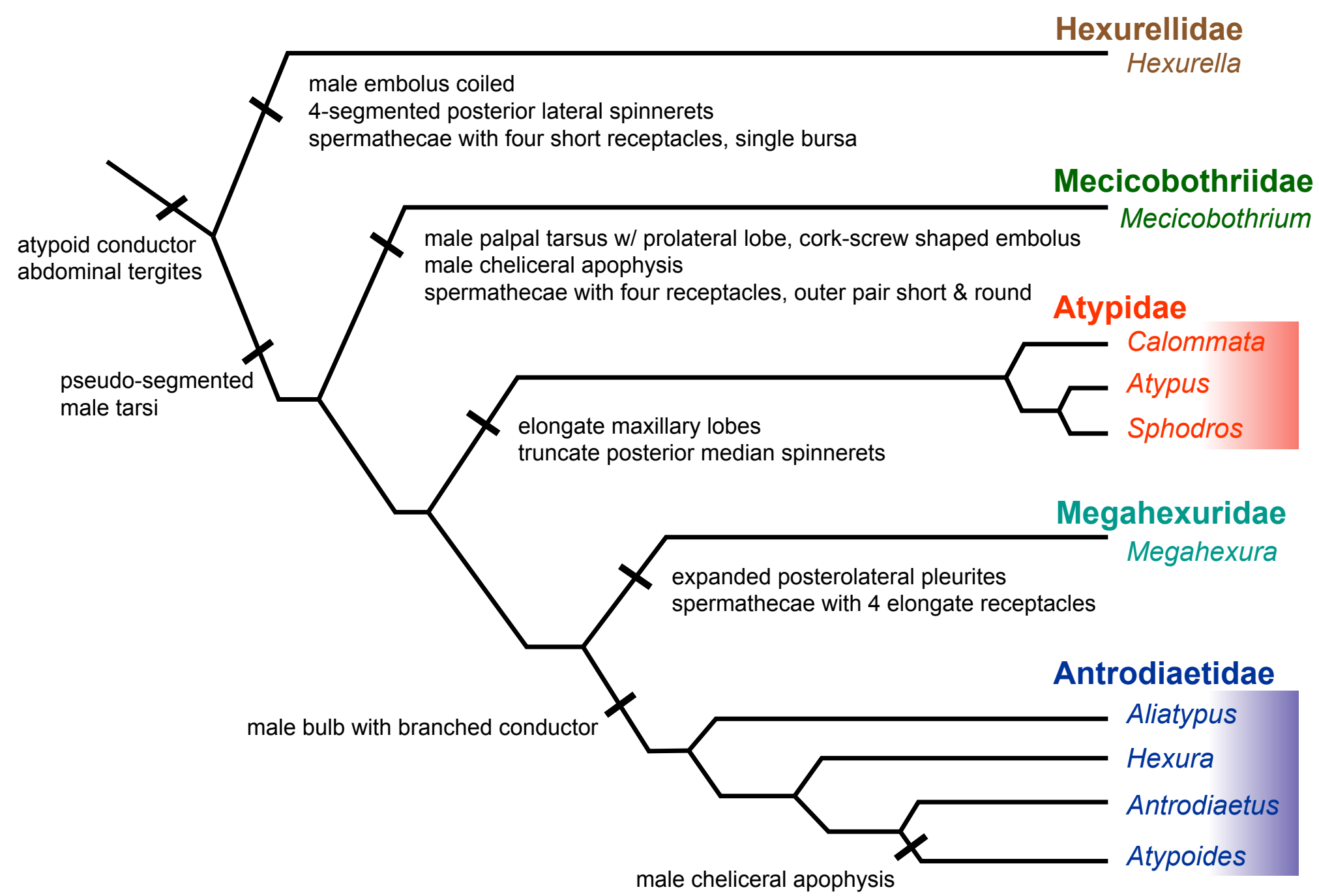

